\title{
PGN Matters: Getting Involved
}

\author{
RUTH SANZ SABIDO, De Montfort University
}

I was recently invited to attend a $\mathrm{PhD}$ conference in the University of Leicester, where I do some part-time teaching. I was asked whether I would like to talk to the delegates about the MeCCSA Postgraduate Network during the conference closing address. As Chair of the PGN, I was very pleased to have an opportunity to promote the Network and what we do. It was a brief, mainly improvised talk, but it was a useful exercise. Some postgraduates welcomed being reminded of our annual PGN conference, and others asked questions about the conference and our mailing list.

However, although everyone there was a PhD researcher, or was about to become one, it was not surprising to find that some $\mathrm{PhD}$ students did not know about the PGN, or they knew about it but did not know how to become part of it, or how to get involved. It was not surprising because, from the same day I took my post as Chair, I became aware of one of the main issues that we face as a Network: the difficulties we usually encounter to work as such. This is due to the very nature of the group: postgraduates are postgraduates for a certain period of time, and then they move on to become part of another "category", whatever this may be. We do not know who our members are, what they need, or how we can support them. We have to work for the postgraduate community based on these uncertainties and with increasingly more limiting constraints, such as, for example, in terms of funding.

The aim of the PGN is to bring together postgraduate students and early career researchers in media, communication and cultural studies from different intellectual traditions and cultural backgrounds in order to form research, and teaching and learning networks and also ensure peer support. We usually find that postgraduates are not aware of the fact that, as long as you are a postgraduate student in an institution which is a member of MeCCSA, you are automatically a member of the Postgraduate Network. So how can we all get involved?

The first step is to subscribe to the MeCCSA-PGN Jiscmail list. This is the most effective way to receive and send details about conferences, funding and jobs. This is where the PGN also distributes information about our annual event, our journal and any other training or development workshops and opportunities. Our website has also been updated recently to include up-to-date information about what we are doing.

Our annual Postgraduate Conference is one of the best platforms to get involved, and there are several ways in which to do so. You can submit a bid to organise the event (the conference will be held in Loughborough in 2012, and at the UEA in 2013, so you can start thinking about submitting a bid for the 2014 event). You can also attend the conference and 
enjoy the wide range of papers, workshops, social events and networking opportunities, as well as presenting and discussing your research within a supportive environment.

Presenting your paper in the conference also provides you with the opportunity to submit your paper for inclusion in the conference edition of our journal, Networking Knowledge. This involves a peer-reviewing process so, apart from having your work reviewed by others, and potentially having it published, you can also become a peer-reviewer and gain further valuable experience. In addition, we have also begun to publish special themed editions of the journal. This, again, provides us with further opportunities, which range from becoming guest editors of the journal to peer-reviewing papers and, of course, this is another platform to publish your work.

Being Chair of the Network has been a rewarding experience and it has allowed me to work with a fantastic team of people who shared the common goal of ensuring the continuation of the PGN and what it does for postgraduates in our subject areas. This brings me to yet another way in which you can get involved: to present yourself as a candidate for one of the roles within our committee. Elections are usually held in July every year at our annual conference, although in 2012 this will exceptionally take place in September during the conference in Loughborough. The committee roles include those of Chair, Secretary, Training, Outreach, Communications and Networking Knowledge Editor. More details about the roles and the elections will be circulated shortly via our Jiscmail list. What skills do you have that could be useful for the Network? How can you contribute to the successful continuation of our activities and events? Do you have any ideas or experience that could benefit the PGN? If you believe you can make a positive contribution to any of these posts, we would like to see hear from you when we release the call for candidates during the summer.

Being part of the PGN Committee involves taking every opportunity to promote the Network, as well as fulfilling the particular requirements of each post. We have received very positive feedback from members of the academic community - postgraduates and non-postgraduates - who have given us encouragement to continue working and to deal with the constraints and challenges that we are all facing at the moment. However, it is also crucial to note that, as a Network for and by postgraduates, it is not only up to the Committee to promote our existence and our work. The Committee represents our postgraduate community, so we would like to have an open dialogue, as a community, so that everyone can be involved by contributing their ideas and knowing that this is a forum to discuss the issues which affect us. This is the best way of ensuring that the work we do remains significant and useful to all our members, so getting in touch is another excellent way of getting involved. In 2014 the Network will celebrate its tenth anniversary and, with the active participation of all of us, I am sure that there are some exciting times to come for the PGN. 